\title{
PREVALENCIA DE FASCIOLOSIS BOVINA EN UNA ZONA DE CALDAS COLOMBIA CON EVIDENCIAS DE LA ENFERMEDAD
}

\section{PREVALENCE OF BOVINE FASCIOLOSIS IN A ZONE OF CALDAS COLOMBIA WITH EVIDENCES OF THE DISEASE}

\author{
Etna Giraldo Pinzón ${ }^{1}$, Jorge Pérez Cárdenas ${ }^{2}$, Sandra Aguilar Marín ${ }^{3}$, Sergio Linares Villalba ${ }^{4}$
}

\begin{abstract}
${ }^{1}$ MVZ, M.Sc., Grupo de investigación en Ciencias Veterinarias CIENVET, Facultad de Ciencias Agropecuarias. Universidad de Caldas, e-mail: julieth.giraldo@ucaldas.edu.co; ${ }^{2}$ Bacteriólogo, M.Sc., Grupo de Investigación BIOSALUD, Facultad de Ciencias para la Salud. Universidad de Caldas, e-mail: labmicro@ucaldas.edu.co; ${ }^{3}$ Licenciada en Biología y Química, M.Sc., Facultad de Ciencias Agropecuarias. Universidad de Caldas, e-mail: sandra.aguilar@ucaldas.edu.co; ${ }^{4}$ MV, M.Sc., Facultad de Ciencias Agropecuarias. Universidad de Caldas, e-mail: sergio.linares@ucaldas.edu.co; Universidad de Caldas. Manizales Colombia. Calle 65 No. 26-10 www.ucaldas.edu.co
\end{abstract}

Rev. U.D.C.A Act. \& Div. Cient. 19(1): 139-148, Enero-Julio, 2016

\section{RESUMEN}

La fasciolosis es una parasitosis que afecta rumiantes, equinos, porcinos, entre otras especies y es causante de grandes pérdidas económicas y puede parasitar humanos. En la presente investigación, se evaluó la frecuencia de la enfermedad por tres métodos de detección, en veintiséis predios, localizados en los municipios del departamento de Caldas, con mayor prevalencia, según reportes de la Central de beneficio de Manizales. Se utilizaron los métodos de coprología, PCR y ELISA, en heces y en suero de bovinos seleccionados aleatoriamente en predios, con el sistema de producción de leche bovina, localizados en los Andes colombianos, entre 1.980$3.721 \mathrm{msnm}$. Se obtuvieron 414 muestras de materia fecal, procesadas con la técnica Dennis modificada. El ADN fue extraído de las heces usando un kit comercial y fue amplificado con cebadores específicos, por PCR convencional. En las muestras de suero, se detectó la presencia de inmunoglobulina G (IgG) contra Fasciola hepatica, a través del uso de un Kit comercial, específico para este fin. La región estudiada, se dividió en cuatro zonas, para efectos del estudio. La prevalencia de la fasciolosis por coprología fue 12,3\%; por Elisa, 19,1\% y por PCR, 67,2\%. La zona tres presentó la mayor proporción de animales positivos, por los tres métodos, con odds ratio elevados y alta significancia estadística; fueron hallados caracoles Limneidos en ambientes acuáticos, aptos para su desarrollo, que permiten perpetuar el inóculo. Se confirma la presencia de fasciolosis bovina en la región estudiada y se requieren hacer estudios adicionales, para validar la PCR, como método para la detección de fasciolosis.

Palabras clave: PCR, Fasciola hepatica, caracoles, zoonosis, Elisa, coprología.

\section{SUMMARY}

Fasciolosis is a parasitic disease that affects ruminants, horses, pigs and other species; it is the cause of significant economic losses and can also parasitize humans. In this research, the frequency of the disease using three detection methods in twenty-six farms, located in the municipalities most prevalent according to reports from the Slaughtering Central of Manizales-Caldas in the department of Caldas was evaluated. The coproscopic, PCR and ELISA methods in feces and serum of randomly selected cattle farms with a system of dairy production, located in the Colombian Andes, between $19803721 \mathrm{~m}$, were used. 414 stool samples were obtained and processed with the Dennis modified technique. DNA was extracted from stool using a commercial kit and was amplified with specific primers for standard PCR. In serum samples, the presence of immunoglobulin G (IgG) against Fasciola hepatica was detected through the use of a specific commercial kit for this purpose. The study area was divided into four zones for the study purposes. The prevalence of fascioliasis by the coproscopic test was $12.3 \%$, by ELISA of $19.1 \%$, and $67.2 \%$ by PCR. Zone three displayed the highest proportion of positive animals by the three methods, with high odds ratio and high statistical significance; lymnaeid snails were found in aquatic environments suitable for development, allowing perpetuate the inoculum. The presence of bovine fasciolosis in the studied region was confirmed; additional studies to validate PCR as a method by the fasciolosis detection are required.

Key words: PCR, Fasciola hepatica, snails, zoonoses, Elisa, coprology. 


\section{INTRODUCCIÓN}

La fasciolosis o distomatosis hepática es una enfermedad parasitaria causada por el trematodo Fasciola hepatica, de importancia veterinaria, debido a las pérdidas económicas que ocasiona en rumiantes, a nivel mundial. Se calcula que más de 300 millones de bovinos y 250 millones de ovinos pastorean en zonas donde se encuentra el trematodo, lo cual, genera un riesgo de infección a millones de animales y de personas, en 61 países, a nivel mundial (Esteban et al. 1997). F. hepatica provoca la helmintiasis de mayor prevalencia en los bovinos del área ecuatorial, con valores que oscilan entre el 30 y el 90\% (Valencia et al. 2005; Wilches et al. 2009; Ticona et al. 2010).

La enfermedad afecta a 2,4 millones de personas, habitantes de focos naturales o zonas de riesgo en todo el mundo, quienes se infectan al ingerir las metacercarias, a través de los alimentos (Mas-Coma et al. 2009); en estas áreas, se presentan ensambles ecológicos, que relacionan parásitos, hospedadores y vectores, en ambientes que facilitan el ciclo biológico del parásito y su persistencia en el medio. Por ello, conocer la dinámica de las poblaciones parasitarias es necesario, para entender la interrelación entre los tres eslabones descritos y la historia de vida del parásito, para lograr su control (Haseeb \& Fried, 1997).

Los bovinos parasitados eliminan los huevos operculados, a través de las heces (Pinheiro et al. 2004); en el agua, éstos embrionan y, posteriormente, se liberan los miracidios, que penetran, activamente, a los moluscos del género Lymnaea; en Colombia, se han identificado Lymnaea ubaquensis, $L$. bogotensis, L. columella y Physa acuta (Velásquez, 2006). La presencia de los hospedadores intermediarios adecuados será la que determine la cantidad de formas infectantes para los animales y para el hombre (Boray et al. 1983; Malone \& Yilma, 1999; Valencia-López et al. 2012). En condiciones apropiadas, después de ingresar al molusco, pierden los cilios y se forman los esporocistos; de allí, se crean una o dos generaciones de redias que, a su vez, darán origen a las cercarias, que salen activamente del caracol al ambiente; después, se recubren con una sustancia mucilaginosa y toman la forma de metacercarias, infectantes para el hombre y para los animales (Urquhart et al. 2001). Éstas, se pueden ingerir, a través del consumo de las pasturas, en vegetales frescos contaminados, como berros, lechugas, espinacas o alfalfa (Marcos \& Terashima, 2007; Valencia et al. 2005).

El parásito requiere de los cuerpos de agua, en especial, de los manantiales y de las quebradas, escenarios de evapotranspiración, que se asocian a condiciones variables de sequía y de humedad. Se deben considerar las situaciones asociadas al cambio climático, como el fenómeno del niño, que da lugar a sequías e inundaciones, que favorecen la per- sistencia y la circulación del parásito, además del ambiente físico, donde se encuentra el parásito, que determina la capacidad de transformación de cercarias a metacercarias, al generar condiciones favorables para la infección de un nuevo hospedador (Mas-Coma et al. 2009).

En Colombia, no se cuenta con una estimación precisa del detrimento asociado a la presencia de este parásito, aunque se han propuesto cifras por encima de 12.000 millones de pesos anuales; el 9,18\% es asociado con el decomiso de hígados parasitados (Becerra, 2001; Pulido et al. 2010; Bernardo et al. 2011). Las regiones con mayor riesgo para la presentación de fasciolosis en el país están ubicadas en la zona andina, donde los huevos de $F$. hepatica, eliminados en ambientes acuáticos, en praderas encharcables, en las zonas de drenaje, en las aguas cristalinas de curso lento, en las plantas, como los berros, son factores que favorecen el desarrollo del ciclo evolutivo y la presencia de los caracoles, indispensables en el mismo (Pinheiro et al. 2004). Las lesiones y las manifestaciones clínicas de la enfermedad en los animales varían de acuerdo al grado de infección, al ingerir las metacercarias y al proceso inflamatorio, debido a la migración de las formas inmaduras hacia el órgano blanco del hospedador definitivo, en el ciclo de vida. De acuerdo a la sintomatología clínica, se puede observar la forma aguda, la subaguda y la crónica de la enfermedad; esta última es la más importante, al presentarse con mayor frecuencia en temporadas de lluvia (Fox et al. 2011). Los animales parasitados muestran una disminución de la productividad, debido a la anemia que se desencadena dos a cinco meses después de la infección, cursa con hipoalbuminemia al inicio, aunque se pueden presentar animales asintomáticos o con manifestaciones agudas de la enfermedad, como hepatomegalia, ictericia y, ocasionalmente, la presencia de abscesos, de fibrosis o de colangitis hiperplásica (Dalton, 1999; Becerra, 2001). A la observación posmortem, el parásito se ubica en los canales biliares de los animales afectados, lo cual, ocasiona el decomiso completo del hígado, en las plantas de beneficio (Mas-Coma et al. 1999; Marcos \& Terashima, 2007).

En Colombia, se registran dos estudios recientes, que describen la presencia de $F$. hepatica: el primero, realizado por Wilches et al. (2009), en el valle de San Nicolás, en el oriente antioqueño, con prevalencias en bovinos por encima del $90 \%$ y en humanos, de $4,9 \%$; el segundo, de Recalde-Reyes et al. (2014), quienes encontraron prevalencias en bovinos, entre 1,14-14,28\%, en algunos municipios del departamento de Quindío. En este mismo estudio, se encontró una persona con anticuerpos contra el parásito; este hallazgo demuestra la presencia de fasciolosis humana, en sitios con infección bovina y puede ser el indicio de un posible problema de salud pública, que no está restringido a estas regiones en particular, sino a todas aquellas en Colombia, asociadas a explotaciones bovinas. 
En el departamento de Caldas, no se han adelantado estudios que evidencien la presencia de fasciolosis bovina; sin embargo, se presentan evidencias de acuerdo con los informes de inspección sanitaria, efectuados en la Central de beneficio de Manizales, donde se detectó un incremento en el reporte de decomisos de hígados bovinos, por la presencia de $F$. hepática, en los canales biliares, entre 2007 y 2009, en animales procedentes de los municipios de Manizales, Neira y Villamaría, ubicados en predios por encima de los 1.900 msnm (datos no publicados). Por tal razón, el objetivo de esta investigación fue determinar la prevalencia de $F$. hepatica, en una muestra aleatoria de explotaciones bovinas de los tres municipios, antes mencionados, utilizando la coprología para la detección de huevos, a través de la técnica de Dennis modificada, que tiene una sensibilidad y especificidad de $73,2 \%$ (IC 95\%=58,4\% - 87,9\%) y 84,2\% (IC 95\%=77,7\% - 90,6\%), respectivamente, con un valor predictivo positivo de $57,7 \%$ (IC 95\%=43,3\% - 72,1\%) y negativo de 91,4\% (IC $95 \%=86,2 \%$ - 96,6\%) (Correa et al. 2016). La PCR para de- tectar secuencias específicas de ADN del parasito con sensibilidad de 96,9\% (IC del 95\% = 87,7-99,3), una especificidad del 99,2 (95\% C.I. = 96,7-99,8) (Kaplan et al. 1997) y una prueba de ELISA para la detección de IgG contra F. hepática, con sensibilidad de 98\% (IC 96-100\%) y especificidad de $96 \%$ (IC, 93-98\%), a un valor de corte de $15 \%$ de positividad.

\section{MATERIALES Y MÉTODOS}

Con el consentimiento del comité de ética para experimentación con animales de la Universidad de Caldas, del 23 de marzo de 2012, se hizo un estudio descriptivo. Se analizaron veintiséis predios elegidos al azar, en los municipios de Manizales, de Neira y de Villamaría, ubicados en la región centrosur de Caldas (Figura 1a y b), por encima de 1.900 msnm, en la Cordillera Central colombiana, entre los $4^{\circ} 55.918^{\prime} \mathrm{N}$ y 75²8.06' W; los predios están dedicados a la explotación de ganado bovino lechero.
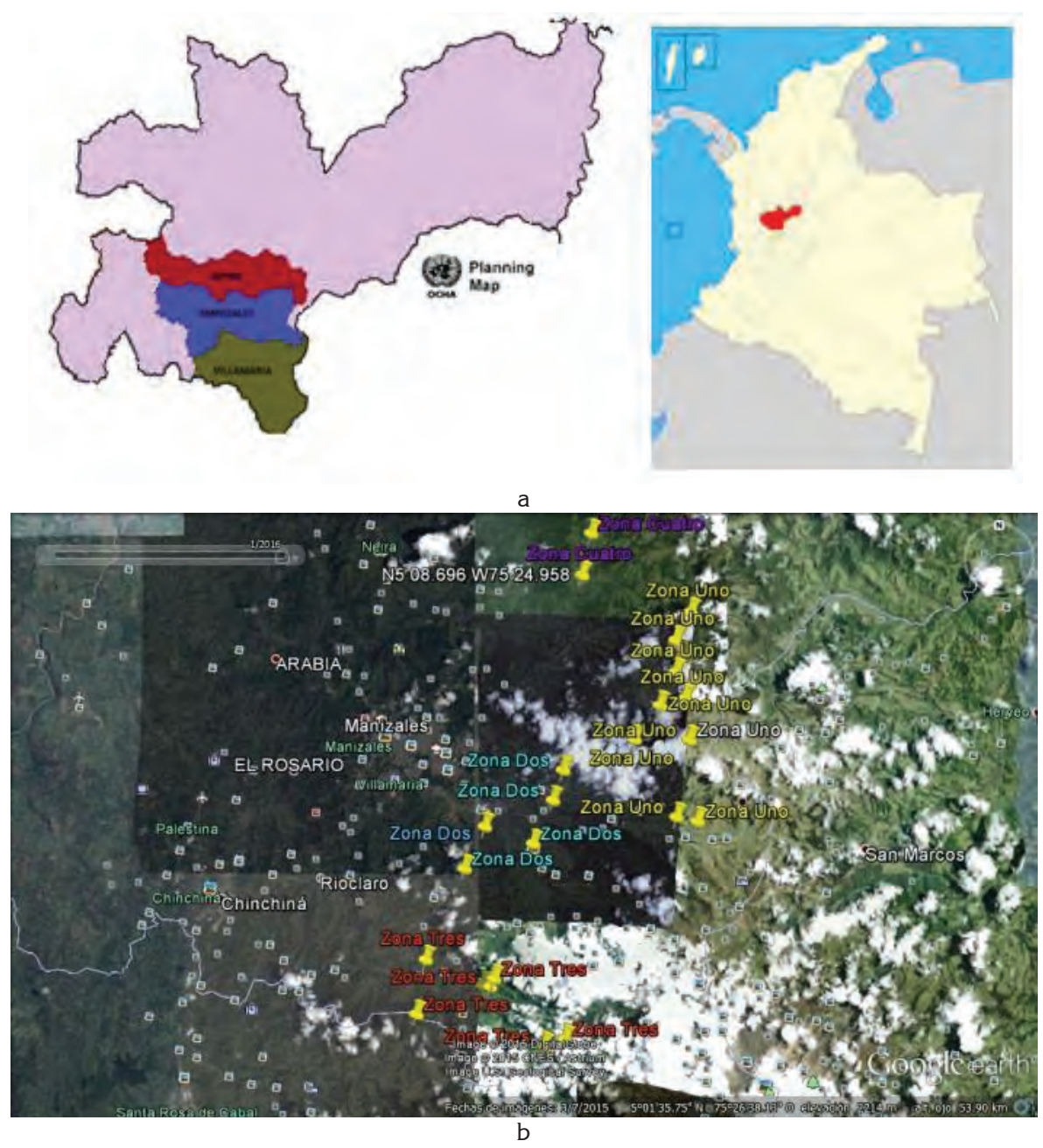

Figura 1: a) Ubicación geográfica del departamento de Caldas y de los municipios del estudio. b) Ubicación geográfica de los predios del estudio. 
El muestreo estuvo conformado por hembras bovinas en producción de leche o con sesenta días antes del parto, de la raza normando (90\%) y sus cruces y, en menor proporción, la raza Holstein y sus cruces (10\%), ampliamente distribuidas en las cuatro zonas ganaderas, en que se dividió el área de estudio, de acuerdo a las características agroecológicas de altura sobre el nivel del mar, fuentes de agua, topografía, temperatura, suelos y humedad relativa.

Se obtuvieron 414 muestras de sangre, para la detección de anticuerpos específicos, por medio de la técnica de ELISA indirecta $\mathrm{BIOX} \AA$ F. hepatica para bovinos, siguiendo las instrucciones del fabricante.

Se analizó igual número de muestras de heces, por la técnica de Dennis modificado (Dennis et al. 1954; Correa et al. 2016); las muestras, se observaron, a través del microscopio óptico y se consideró como positiva, la que tuviera, al me- nos, un huevo de F. hepatica. En cada sedimento, se hizo la extracción de ADN, con el kit fecal Ultraclean ${ }^{\circledR}$ Laboratorios MoBio; dicho procedimiento, se realizó de acuerdo a las instrucciones del fabricante. Para la amplificación, se empleó un termociclador DNAEngine ${ }^{\circledR}$ BIO-RAD PTC 200, utilizando el siguiente protocolo: desnaturalización inicial, a $95^{\circ} \mathrm{C}$, 5 min; 40 ciclos de desnaturalización, a $95^{\circ} \mathrm{C}$, por $1 \mathrm{~min}$; alineación, a $55,4^{\circ} \mathrm{C}, 1 \mathrm{~min}$; extensión, a $72^{\circ} \mathrm{C}$, por $1 \mathrm{~min}$. Se finalizó la amplificación, con una extensión final a $72^{\circ} \mathrm{C}$, por 10 min. Los ADN obtenidos fueron visualizados en geles de agarosa al $2 \%$, teñidos con bromuro de ethidio (Figura 2). Se empleó como marcador de peso molecular, el Hyperladder $\mathrm{V}($ Laboratories, que presenta bandas entre 25 a 500p. Para la identificación del ADN de F. hepática, se usaron cebadores para la amplificación de una secuencia repetitiva de $124 \mathrm{pb}$, que constituye, aproximadamente, el $15 \%$ del genoma del parásito (Kaplan et al. 1995; 1997; Caron et al. 2007; 2011; 2014).

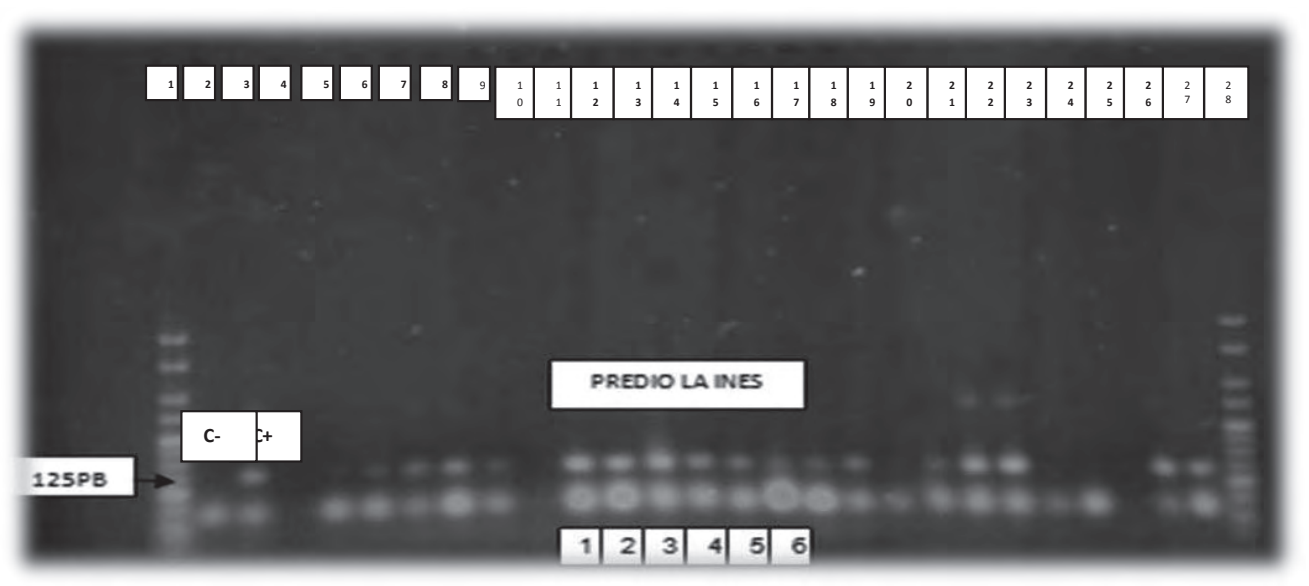

Figura 2. Gel de agarosa al 2\%, con tres predios evaluados por la técnica PCR convencional, para Fasciola hepatica. Carril 1: Marcador de peso molecular (25pb-500pb); Carril 2: Control negativo; Carril 3: Control positivo; Carril 5-9: muestras predio La Vega; Carril 11-16: Predio La Inés; Carril 17-27: Predio La Laguna: Carril 28: Marcador de peso molecular.

Se calculó el porcentaje de animales infectados con el parásito, sobre el total de bovinos evaluados; para el análisis estadístico, se aplicó la prueba de $\chi^{i^{2}}$, se calculó el valor mid-p y, además, el Odds ratio con sus intervalos de confianza, para evaluar la posible asociación entre factores de riesgo y las muestras positivas.

Los estudios parasitológicos fueron complementados con la identificación de los caracoles procedentes de la zona de estudio y con la búsqueda de las formas intramolusco de $F$. hepatica. Para obtenerlos, se visitaron los sitios con afloramientos naturales de agua dulce, bebederos, canales de agua y quebradas de los 26 predios del estudio; se buscó en la vegetación asociada a las zonas húmedas de cada predio; para la captura, se utilizó la metodología por unidad de esfuerzo (Rabinovich, 1980), definida como el número de caracoles colectados en un período de 30 minutos; se emplearon tamices colectores y se estableció un transecto longitudinal en la dirección del cauce; además, se realizó la búsqueda visual de caracoles sobre las plantas y demás sustratos de la zona inundada.

\section{RESULTADOS Y DISCUSIÓN}

La prevalencia de la fasciolosis calculada por el método de coprología fue del 12,3\%; la zona dos y tres presentaron animales positivos por este método, con mayor prevalencia en esta última zona, donde se registró una alta significancia es- 
tadística y una alta probabilidad de adquisición de la enfermedad ( $<<0,01 ;$ OR:96; IC95\%:27-600) (Tabla 1). Este resultado se puede atribuir a la sensibilidad de la técnica utilizada.

La prevalencia de fasciolosis en los bovinos analizados por ELISA fue de 19,1\%; todas las zonas evaluadas presenta- ron animales con anticuerpos frente a $F$. hepatica. La zona tres, nuevamente, presentó la mayor frecuencia de animales positivos, con una alta significancia estadística y alto riesgo de adquisición de la enfermedad ( $\mathrm{p}<0,01$; OR: 10,7; IC95\%:6,1-19) (Tabla 2).

Tabla 1. Prevalencia de F. hepatica en bovinos por zona geográfica, de acuerdo a los resultados del coprológico, en la región centro sur, del departamento de Caldas, Colombia.

\begin{tabular}{|c|c|c|c|c|c|c|}
\hline ZONAS & TOTAL & POS & PREV (\%) & P & OR & IC (\%) \\
\hline 1 & 159 & 0 & 0 & - & - & - \\
\hline 2 & 97 & 2 & 2,1 & $<0,01$ & 0,11 & $0,01-0,4$ \\
\hline 3 & 122 & 49 & 40 & $<0,01$ & 96 & $27-600$ \\
\hline 4 & 36 & 0 & 0,0 & - & - & - \\
\hline TOTAL & 414 & 51 & 12,3 & & & \\
\hline
\end{tabular}

POS: Número de positivos; PREV: Prevalencia; P: Valor de p calculado por MID-p exacto; OR: Odds ratio, calculado con MID-p exacto; IC: Intervalo de confianza.

Tabla 2. Prevalencia de F. hepatica en bovinos por la técnica ELISA, en la región centro sur, del departamento de Caldas, Colombia.

\begin{tabular}{|c|c|c|c|c|c|c|}
\hline ZONAS & TOTAL & POS & PREV (\%) & P & OR & IC (\%) \\
\hline 1 & 159 & 3 & 1,9 & $<0,01$ & 0,04 & $0,01-0,13$ \\
\hline 2 & 97 & 14 & 14,4 & 0,18 & 0,65 & $0,3-1,2$ \\
\hline 3 & 122 & 57 & 46,7 & $<0,01$ & 10,7 & $6,1-19$ \\
\hline 4 & 36 & 5 & 13,9 & 0,21 & 0,7 & $0,2-1,7$ \\
\hline TOTAL & 414 & 79 & 19,1 & & & \\
\hline
\end{tabular}

POS: Número de positivos; PREV: Prevalencia; P: Valor de p calculado por MID-p exacto; OR: Odds ratio, calculado con MID-p exacto; IC: Intervalo de confianza.

La prevalencia de fasciolosis para los bovinos en los predios evaluados por PCR convencional fue del $67,2 \%$, con animales positivos en la zona 2 y 3 (Tabla 3); este valor fue mayor al obtenido por los otros métodos utilizados. Es necesario aclarar que no se pudo analizar las muestras de la zona 1, debido a que las mismas fueron conservadas en formalina al $10 \%$ y no fue posible obtener el ADN, por la degradación del mismo. De manera similar a lo obtenido en los resultados anteriores, se observa una alta significancia estadística y alta probabilidad de adquisición de la enfermedad en la zona 3 (p:<0,01 OR: 2,6 IC95\%: 1,34-5,12) (Tabla 4).
Un factor en común en los tres métodos utilizados es la alta significancia estadística y valores de odds ratio altos, acompañados con intervalos de confianza mayores de 1 , presentes en la zona 3 (Tabla 1, 2 y 3). Estos valores elevados pueden estar vinculados a diferentes factores de riesgo asociados con la enfermedad, tales como la presencia de caracoles, que son reportados como hospederos intermediarios del parásito, que se encuentran en las pasturas y en las plantas acuáticas, en las que se pueden implantar las metacercarias.

Aunque los métodos coproparasitológicos son de gran utilidad y de bajo costo (Duthaler et al. 2010; Godoy et al. 2010) son moderadamente sensibles para detectar la infección por 
Tabla 3. Prevalencia de $F$. hepatica en bovinos por PCR convencional, en la región centro sur, del departamento de Caldas, Colombia.

\begin{tabular}{|c|c|c|c|c|c|c|}
\hline ZONA & TOTAL & POS & PREV (\%) & P & OR & IC (\%) \\
\hline $\mathbf{2}$ & 33 & 25 & 75,8 & 0,06 & 2,2 & $0,94-5,5$ \\
\hline $\mathbf{3}$ & 114 & 79 & 69,3 & $<0,01$ & 2,61 & $1,34-5,12$ \\
\hline $\mathbf{4}$ & 21 & 0 & 0,00 & - & - & - \\
\hline TOTAL & 168 & 104 & 67,2 & & & - \\
\hline
\end{tabular}

POS: Número de positivos; PREV: Prevalencia; P: valor de p calculado por MID-p exacto; OR: Odds ratio, calculado con MID-p exacto; IC: Intervalo de confianza.

Tabla 4. Prevalencia de F. hepatica en bovinos, en la región centro sur del departamento de Caldas, Colombia, según la altura sobre el nivel del mar y método de detección utilizado.

\begin{tabular}{|c|c|c|c|c|c|}
\hline \multicolumn{6}{|c|}{ COPROLÓGICO } \\
\hline $\begin{array}{l}\text { RANGOS } \\
\text { DE ALTURA }\end{array}$ & POS & NEG & P & OR & IC \\
\hline $1900-2500$ & 47 & 153 & $<0,01$ & 16,04 & $6,12-53,33$ \\
\hline $2501-3100$ & 4 & 51 & 0,22 & 0,52 & $0,15-1,4$ \\
\hline $3101-3800$ & 0 & 159 & NC & $\mathrm{NC}$ & $\mathrm{NC}$ \\
\hline \multicolumn{6}{|c|}{ ELISAS } \\
\hline $1900-2500$ & 73 & 127 & $<0,001$ & 19,8 & $8,8-51,5$ \\
\hline 2501-3100 & 3 & 52 & $<0,01$ & 0,21 & $0,051-0,63$ \\
\hline $3101-3800$ & 3 & 156 & $<0,001$ & 0,045 & $0,01-0,13$ \\
\hline \multicolumn{6}{|c|}{ PCR } \\
\hline $1900-2500$ & 82 & 41 & 0,03 & 2,08 & $1,03-4,2$ \\
\hline 2501-3100 & 22 & 23 & 0,03 & 0,48 & $0,23-0,96$ \\
\hline $3101-3800$ & 0 & 0 & $\mathrm{NC}$ & $\mathrm{NC}$ & $\mathrm{NC}$ \\
\hline
\end{tabular}

POS: Muestras positivas; NEG: Muestras negativas; P: Valor de p; OR: Odds ratio; IC: Intervalo de confianza al $95 \%$.

F. hepatica, cuando la emisión de huevos al medio es moderada y alta, lo que coincide con la infección aguda y crónica, respectivamente. Los métodos tienen reducida sensibilidad al encontrarse en infecciones de baja intensidad o en la fase migratoria del parásito, después de haber sido ingerida su forma infectante (Fredes et al. 2001; Duthaler et al. 2010).

Estudios en Colombia indican que el parásito afecta al 25\% de los bovinos en producción lechera; de allí, se generan pérdidas, por la disminución en la producción de leche y de carne (Becerra, 2001). De manera similar, Wilches et al. (2009), reportaron en el departamento de Antioquia, prevalencias mayores del $40 \%$; en estos estudios, el método de diagnóstico empleado fue el coprológico, por lo tanto, si se comparan estos resultados con los obtenidos por el mismo método en el presente estudio, se podría concluir que la prevalencia de la fasciolosis, en esta zona de Caldas, es intermedia y representa un problema importante de salud animal.

Al comparar los resultados obtenidos en el coprológico con respecto a las pruebas de Elisa, se evidenció que 33 de las 51 muestras positivas por el coprológico fueron también positivas para la presencia de IgG contra F. hepática. El grado de concordancia de ambos métodos fue moderado al aplicar el índice kappa $(k=0,421 ; P=<0.01)$. Dentro de los factores asociados con este resultado, se debe tener en cuenta el grado de parasitismo de los animales; la presencia de baja cantidad de parásitos adultos disminuye la probabilidad de encontrar huevos en las heces, factor que puede estar asociado, también, con la ausencia de cambios patológicos y de 
sintomatología en el animal. Los estímulos antigénicos del parásito al inicio, durante su migración y el paso al estado adulto, generan una respuesta inmunológica, asociada con la producción de anticuerpos, que alcanzan a ser detectados por los métodos implementados para este propósito. Algunos estudios han demostrado que las IgM y las IgE se elevan algunas semanas después de la infección (Salimi-Bejestani et al. 2005); la IgG puede ser detectada por tres a siete meses después del tratamiento efectivo contra F. hepatica (Gorman et al. 1998; Castro et al. 2000), generando una huella inmunológica del proceso infeccioso previo.

Contrasta la alta frecuencia de animales positivos por PCR con los obtenidos por medio del coprológico y la prueba de ELISA; los índices de concordancia, al comparar los tres métodos, muestran que la misma es baja, siendo estadísticamente significante cuando se compara el coprológico con la PCR (k: 0,28 P: <0,01). Este hallazgo puede estar asociado a la mayor sensibilidad de la prueba molecular (Kaplan et al. 1995; Cucher et al. 2006; Caron et al. 2011; 2014) y podría ser un indicador de la baja sensibilidad del coprológico, para la detección de los huevos del parásito; sin embargo, se requieren estudios adicionales, que puedan servir para corroborar este resultado.

La mayoría de las muestras analizadas por el método molecular procedieron de la zona dos y tres, áreas en las que se obtuvieron las frecuencias más altas de coprológicos positivos y de anticuerpos frente al parásito (Tabla 1 y 2). Se podría argumentar que la amplificación realizada no es específica para Fasciola sp.; por esta razón, se procedió a analizar el grado de anillamiento de los cebadores utilizados en el proceso de amplificación con otras secuencias no asociadas con $F$. hepatica, con el uso del programa basic alignment search tool (BLAST), del Instituto Nacional de Salud de Estados Unidos. Se observó, que dichos cebadores no se alineaban con secuencias asociadas con genes presentes en bovinos, con plantas que hicieran parte de su alimentación, ni con microorganismos que pudieran estar presentes en su tracto digestivo. En cuanto a la sensibilidad del PCR, ensayos realizados por Kaplan et al. (1995) y Caron et al. (2014), han demostrado que la misma puede detectar la presencia del genoma de $F$. hepatica en caracoles, infectados con un solo miracidio.

En el presente estudio, se buscaron en las cuatro zonas de muestreo la presencia de caracoles que pudieran ser hospederos intermediarios de F. hepatica; dichos moluscos fueron encontrados en tres fincas, de la zona dos y en tres predios, de la zona tres. De los caracoles encontrados en dichos predios, solamente Lymnaea columella se ha asociado con la trasmisión de F. hepatica, en Colombia (López et al. 2008; Wilches et al. 2009). Los caracoles, se albergaron en al menos diez especies diferentes de plantas, siendo la más fre- cuentada los berros (Nasturtium officinale) (Giraldo \& Álvarez, 2013), planta preferida por los herbívoros domésticos, en razón de su palatabilidad y digestibilidad, que coincide con los registros de otros países (Prepelitchi et al. 2011).

Tanto los caracoles como las plantas, se encuentran en fuentes de agua tomadas por los predios rurales para su abastecimiento, en especial, manantiales y quebradas; los bovinos tienen libre acceso a dichas fuentes, que generan la contaminación permanente del agua, con materias fecales infectadas y la ingesta de agua y de vegetación con metacercarias, que perpetúan, de manera indefinida, la infección por este trematodo. El análisis de los caracoles obtenidos no demostró la presencia de formas intramolusco del parásito; sin embargo, otros estudios han encontrado que los métodos microscópicos para la búsqueda de estas formas larvarias, no es tan sensible como el uso de métodos moleculares (Caron et al. 2011), los cuales, no pudieron ser utilizados por limitaciones presupuestales.

Los predios en los que se detectó la presencia de $L$. columella estuvieron entre los 1.980 y $3.800 \mathrm{msnm}$; la mayoría de ellos, entre los 1.900 y los $2.500 \mathrm{msnm}$ (5 predios). Al analizar si había asociación estadísticamente significativa entre el piso térmico y las muestras positivas, se registró que en todos los métodos utilizados hubo significancia estadística en el rango de 1.900 a 2.500msnm (Tabla 4), siendo este resultado un indicio de la importancia de este hospedero intermediario en la transmisión y mantenimiento de F. hepática, en dichos predios.

De los resultados obtenidos, se confirma la presencia de fasciolosis en esta región de Caldas; si se tiene en cuenta la prevalencia encontrada por el método molecular, ésta es superior a lo observado en otros estudios adelantados en Colombia. El uso del método molecular podría evidenciar un subdiagnóstico de la enfermedad, con el uso de la técnica coprológica, como la prueba de ELISA; métodos que al ser aplicados en zonas con baja endemicidad podrían generar alto porcentaje de falsos negativos. Se requiere hacer estudios que permitan validar la técnica molecular, como un método de detección de fasciolosis bovina.

La zona tres es la que presenta el mayor número de animales positivos; indica este hallazgo, la presencia de factores de riesgo que contribuyen a la dispersión del parásito, en la población bovina de esta zona, en la cual, se identifican los hospedadores intermediarios relacionados con la transmisión del parásito; la interacción entre especies introducidas del viejo mundo (bovinos, Fasciola, Lymnaea columella e, incluso, el hospedero más frecuente del caracol, Nasturtium officinale), han generado un ensamble que, a su vez, se constituye en foco endémico, en la región norte de Suramérica. 
Se recomienda hacer estudios adicionales que confirmen los resultados obtenidos e identifiquen los factores de riesgo que incrementan la prevalencia de la enfermedad, utilizando, por ejemplo, métodos moleculares, que permitan detectar la presencia de cercarias y metacercarias en el agua, en las plantas o la presencia de formas larvarias dentro de los caracoles, asociados a este ecosistema.

De igual manera, se recomienda el uso de métodos moleculares, adecuadamente validados, para la detección del parásito en heces, ya que, de acuerdo a los resultados obtenidos, podrían detectar una mayor proporción de animales infectados, que tienen una baja carga parasitaria.

Conflictos de intereses: El manuscrito fue preparado y revisado con la participación de todos los autores, quienes declaramos que no existe conflicto de intereses que ponga en riesgo la validez de los resultados presentados; además, que no se tienen ninguna relación comercial o contractual con las casas comerciales proveedoras de los materiales y reactivos utilizados en esta investigación. Financiación: Este estudio fue financiado por la Vicerrectoría de Investigaciones y Posgrados de la Universidad de Caldas.

\section{BIBLIOGRAFÍA}

1. BECERRA, W. 2001.Consideraciones sobre estrategias sostenibles para el control de Fasciola hepatica en Latinoamérica. Rev. Col. Cienc. Pec. 14(1):28-35.

2. BERNARDO, C.C.; CARNEIRO, M.B.; AVELAR, B.R.; DONATELE, D.M.; MARTINS, I.V.F.; PEREIRA, M.J.S. 2011. Prevalence of liver condemnation due to bovine fasciolosis in southern Espírito Santo: temporal distribution and economic losses. Rev. Bras. Parasitol Vet. 20(1):49-53.

3. BORAY, J.C.; CROWFOOT, P.D.; STRONG, M.B. 1983. Treatment of immature and mature Fasciola hepatica infections in sheep with triclabendazole. Vet. Record. 113(14):315-322.

4. CARON, Y.; MARTENS, K.; LEMPEREUR, L.; SAEGERMAN, C.; LOSSON, B. 2014. New insight in lymnaeid snails (Mollusca, Gastropoda) as intermediate hosts of Fasciola hepatica (Trematoda, Digenea) in Belgium and Luxembourg. Parasites \& Vectors. (Reino Unido). 7:66.

5. CARON, Y.; LASRI, S.; LOSSON, B. 2007. Fasciola hepatica: an assessment on the vectorial capacity of Radix labiata and $R$. balthica commonly found in Belgium. Vet. Parasitol. 149(1-2):95-103.
6. CARON, Y.; RIGHI, S.; LEMPEREUR, L.; SAEGERMAN, C.; LOSSON, B. 2011. An optimized DNA extraction and multiplex PCR for the detection of Fasciola sp. in lymnaeid snails. Vet. Parasitol. 178(1-2):93-99.

7. CASTRO, E.; FREYRE, A.; HERNANDEZ, Z. 2000. Serological responses of cattle after treatment and during natural re-infection with Fasciola hepatica measured using a dot-ELISA system. Vet. Parasitol. 90(3):201208.

8. CORREA, S.; MARTÍNEZ, Y.L.; LÓPEZ, J.L.; VELÁSQUEZ, L.E. 2016. Evaluación de la técnica parasitológica Dennis modificada para el diagnóstico de fasciolosis bovina. Biomédica. 36(2) Publicación provisional.

9. CUCHER, M.A.; CARNEVALE, S.; PREPELITCHI, L.; WISNEVESKY-COLLI, C. 2006. PCR diagnosis of Fasciola hepatica in field-collected Lymnaea columella and Lymnaea viatrix snails. Vet. Parasitol. 137(1-2):74-82.

10. DALTON, J.P. 1999. Editor. Epidemiology and control. En: Fasciolosis. Oxford, UK: CABI publ. p.113-149.

11. DENNIS, W.; STONE, W.; SWANSON, L. 1954. A new laboratory and field diagnostic test for fluke ova in feces. Florida Agr. Exp. Station J. Series. 172:47-50.

12. DUTHALER, U.; RINALDI, L.; MAURELLI, M.P.; VARGAS, M.; UTZINGER, J.; CRINGOLI, G.; KEISER J. 2010. Fasciola hepatica: Comparison of the sedimentation and FLOTAC techniques for the detection and quantification of faecal egg counts in rats. Exp. Parasitol. 126(2):161-166.

13. ESTEBAN, J.G.; FLORES, A.; ANGLES, R.; STRAUSS, W.; AGUIRRE, C.; MAS-COMA, S. 1997. A population-based coprological study of human fascioliasis in a hyperendemic area of the Bolivian Altiplano. Trop. Med. Int. Health (Reino Unido). 2(7):695-699.

14. FREDES, F.; SÁNCHEZ, C.; GORMAN, T.; ALCAINO, H. 2001. Purificación de antígenos de Fasciola hepatica mediante electroelución y su aplicación inmunodiagnóstica en la infección animal. Parasitol. Día. (Chile). 25(1-2):19-23.

15. FOX, N.J.; WHITE, P.C.L.; MCCLEAN, C.J.; MARION, G.; EVANS, A.; HUTCHINGS, M.R. 2011. Predicting Impacts of Climate Change on Fasciola hepatica Risk. PLoS ONE 6(1): e16126. 
16. GIRALDO, E.J.; ÁLVAREZ, L.M. 2013. Registro de plantas hospederas de caracoles Lymnaeidae (Mollusca: Gastropoda), vectores de Fasciola hepatica (Linnaeus, 1758), en humedales de la región central andina colombiana. Vet. Zoot. 7(2):63-74.

17. GODOY M., Y.; ROQUE L., E.; RODRIGUEZ F., R. 2010. Diagnóstico coproparasitológico de Fasciola hepatica en ganado bovino en una empresa pecuaria cubana. Rev. Inv. Vet. Perú. 21(2):175-179.

18. GORMAN, T.; SÁNCHEZ, R.; FREDES, F.; ALCAINO, H. 1998. Inmunodiagnóstico de fasciolosis bovina mediante ELISA y Western Blot. Parasitol. Día. 22(12):16-22.

19. HASEEB, M.A.; FRIED, B. 1997. Modes of transmissions of trematode infections and their control. In: Fried, B.; Graczyk, T. (Eds). Trematode Biology. CRC Press (Boca Raton). 466p.

20. KAPLAN, R.M.; DAME, J.B.; REDDY, G.R.; COURTNEY, C.H. 1997. The prevalence of Fasciola hepatica in its snail intermediate host determined by DNA probe assay. Int. J. Parasitol (Reino Unido). 27(12):15851593.

21. KAPLAN, R.M.; DAME, J.B.; REDDY, G.R.; COURTNEY, C.H. 1995. A repetitive DNA probe for the sensitive detection of Fasciola hepatica infected snails. Int. J. Parasitol. 25:601-610.

22. LÓPEZ, L.P.; ROMERO, J.; VELÁSQUEZ, L.E. 2008. Aislamiento de Paramphistomidae en vacas de leche y en el hospedador intermediario (Lymnaea truncatula y Lymnes columella) en una granja del trópico alto en el occidente de Colombia. Rev. Col. Cienc. Pec. 21(1):9-18.

23. MALONE, J.B.; YILMA, J.M. 1999. Predicting outbreaks of fasciolosis: from ollerenshaw to satellites. In: Dalton, J.P. (ed.). Fasciolosis. Dublin: School of Biotechnology. p.151-182.

24. MARCOS, L.A.; TERASHIMA, A. 2007. Update on human fascioliasis in Peru: Diagnosis, treatment and clinical classification proposal. Neotrop. Helminthol. (Perú). 1(2):85-104.

25. MAS-COMA, S.; ANGLES, R.; ESTEBAN, J.G.; BUCHON, P.; FRANKEN, M.; SATRAUSS, W. 1999. The Northern Bolivian Altiplano: a region highly endemic for human fascioliasis. Trop. Med. Int. Health (Reino Unido). 4(6):454-467.
26. MAS-COMA, S.; VALERO, M.A.; BARGUES, M.D. 2009. Fasciola, lymnaeids and human fascioliasis, with a global overview on disease transmission, epidemiology, evolutionary genetics, molecular epidemiology and control. Adv. Parasitol. 69:41-146.

27. PINHEIRO, J.; MALDONADO, A.J.; ATTIAS, M.; LANFREDI, R.M. 2004. Morphology of the rediae of Echinostoma paraensei (Trematoda: Echinostomatidae) from its intermediate host Lymnaea columella (Mollusca, Gastropoda). Parasitology research (Alemania). 93(3):171-177.

28. PREPELITCHI, L.; PIETROKOVSKY, S.; KLEIMAN, F.; RUBEL, D.; ISSIA, L.; MORIENA, R.; RACIOPPI, O.; ÁLVAREZ, J.; WISNIVESKY-COLLI, C. 2011. Population structure and dynamics of Lymnaea columella (Say, 1817) (Gastropoda: Lymnaeidae) in wetlands of northeastern Argentina. Zool. Studies (Taiwan). 50(2):164-176.

29. PULIDO, A.; CASTAÑEDA, R.; ARBELÁEZ, G. 2010. Fasciolosis hepática, pedagogía de diagnóstico por laboratorio y su situación en Colombia. REDVET. 12:1-11.

30. RABINOVICH, J.E. 1980. Introducción a la ecología de Poblaciones Animales. México. Editorial Continental S.A. 313p.

31. RECALDE-REYES, D.P.; PADILLA SANABRIA, L.; GIRALDO GIRALDO, M.I.; TORO SEGOVIA, L.J.; GONZALEZ, M.M.; CASTAÑO OSORIO, J.C. 2014. Prevalencia de Fasciola hepatica, en humanos y bovinos en el departamento del Quindío-Colombia 20122013. Infectio (Colombia). 18(4):153-157.

32. SALIMI-BEJESTANI, M.R.; MCGARRY, J.W.; FELSTEAD, S.; ORTIZ, P.; AKCA, A.; WILLIAMS, D.J. 2005. Development of an antibody-detection ELISA for Fasciola hepatica and its evaluation against a commercially available test. Res. Vet. Sci. 78:177-181.

33. TICONA, D.S.; CHÁVEZ, A.; CASAS, G.; CHAVERA, C.A.; LI, E.O. 2010. Prevalencia de Fasciola hepatica en bovinos y ovinos de Vilcashuamán, Ayacucho. Rev. Inv. Vet. Perú. 21:168-174.

34. URQUHART, G.M.; ARMOUR, J.; DUNCAN, J.; DUNN, A.M.; JENNINGS, F.W. 2001. Parasitologia Veterinaria. Editorial Acribia S.A. Segunda Edición. Zaragoza: Impreso en Grafic Rm Color. S.L. p.115-130. 
35. VALENCIA, M.N.; PARIONA D., A.; HUAMÁN A., M.; MIRANDA M., F.; QUINTANILLA C., S.; GONZALES A., A. 2005. Seroprevalencia de fasciolosis en escolares y en ganado vacuno en la provincia de Huancavelica, Perú. Rev. Peru Med. Exp. Salud Públ. 22(2):96-102.

36. VALENCIA-LÓPEZ, N.; MALONE, J.B.; CARMONA, C.G.; VELÁSQUEZ, L.E. 2012. Climate-based risk models for Fasciola hepatica in Colombia. Geospat Health. 6(3):67-85.

37. VELÁSQUEZ, L.E. 2006. Synonymy between Lymnaea bogotensis Pilsbry, 1935 and Lymnaea cou- sini Jousseaume, 1887 (Gastropoda: Lymnaeidae). Mem. Inst. Oswaldo Cruz. 101(7):795-799.

38. WILCHES, C.; JARAMILLO, J.G.; MUÑOZ, D.L.; ROBLEDO, S.M.; VÉLEZ, I.D. 2009. Presencia de infestación por Fasciola hepatica en habitantes del valle de San Nicolás, oriente antioqueño. Infectio 13(2):9299.

Recibido: Octubre 6 de 2015

Aceptado: Febrero 5 de 2016

Cómo citar:

Giraldo Pinzón, E.; Pérez Cardenas, J.; Aguilar Marín, S.; Linares Villaba, S. Prevalencia de fasciolosis bovina en una zona de Caldas Colombia con evidencias de la enfermedad. Rev. U.D.C.A Act. \& Div. Cient. 19(2): 139-148. 